\title{
Evaluation and Demonstration of the BNFL lonsens
}

by

S. R. Salaymeh

Westinghouse Savannah River Company

Savannah River Site

Aiken, South Carolina 29808

C. May

C. Luff

DOE Contract No. DE-AC09-96SR18500

This paper was prepared in connection with work done under the above contract number with the U.S.

Department of Energy. By acceptance of this paper, the publisher and/or recipient acknowledges the U.S.

Government's right to retain a nonexclusive, royalty-free license in and to any copyright covering this paper, along with the right to reproduce and to authorize others to reproduce all or part of the copyrighted paper. 


\section{DISCLAIMER}

This report was prepared as an account of work sponsored by an agency of the United States Government. Neither the United States Government nor any agency thereof, nor any of their employees, make any warranty, express or implied, or assumes any legal liability or responsibility for the accuracy, completeness, or usefuiness of any information, apparatus, product, or process disclosed, or represents that its use would not infringe privately owned rights. Reference herein to any specific commercial product, process, or service by trade name, trademark, manufacturer, or otherwise does not necessarily constitute or imply its endorsement, recommendation, or favoring by the United States Government or any agency thereof. The views and opinions of authors expressed herein do not necessarily state or reflect those of the United States Government or any agency thereof. 


\section{DISCLAIMER}

Portions of this document may be illegible in electronic image products. Images are produced from the best available original document. 
WSRC-TR-99-00150

Revision 0

\title{
Evaluation and Demonstration of the BNFL Ionsens (U)
}

\author{
Saleem R. Salaymeh \\ Cecil May \\ Graig Luff
}

Unclassified

Does Not Contain Unclassified Controlled Nuclear Information (UCNI)

April 27, 1999

Wesṭinghouse Sạannah River Company

Savannah River Site

Aiken, SC 29808

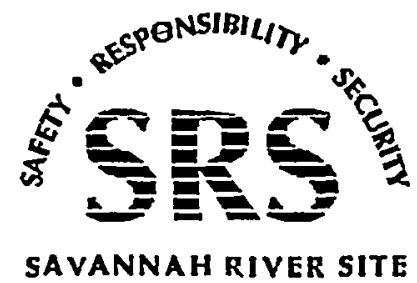


Keywords:

Characterization Potentially Contaminated

Free release $321-\mathrm{M}$

$\therefore$ 105-C

Decontamination

Classification: $\mathrm{U}$

\section{Evaluation and Demonstration of the BNFL Ionsens (U)}

\section{Saleem R. Salaymeh, et al}

Publication Date: April 27, 1999

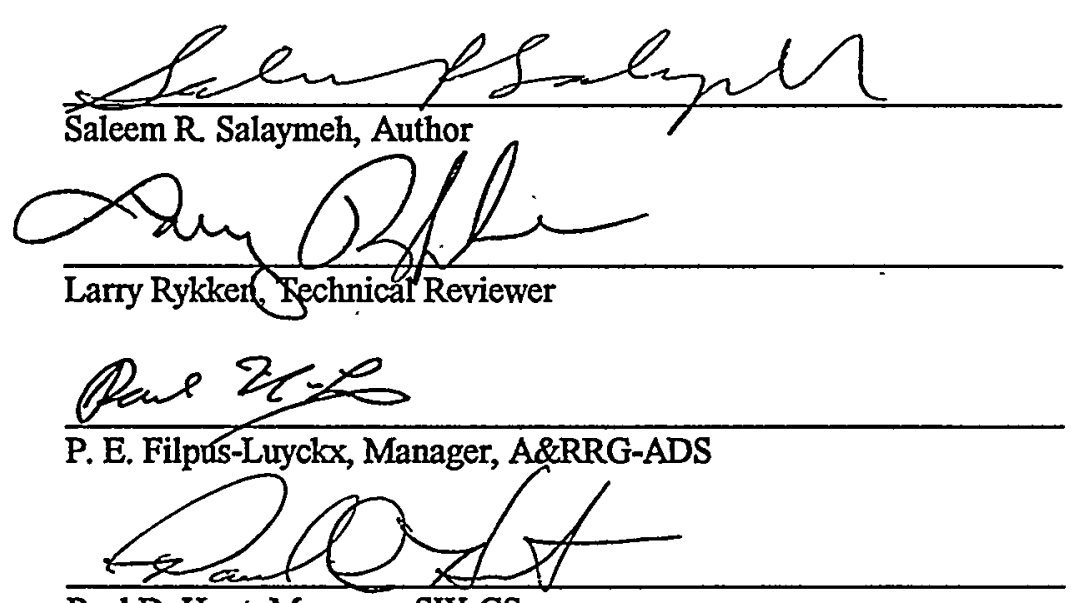

Paul D. Hunt, Manager, SW-GS

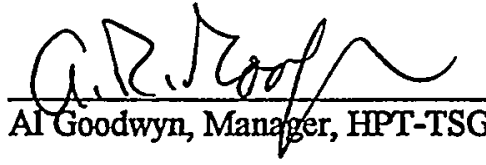

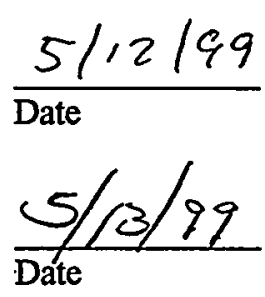
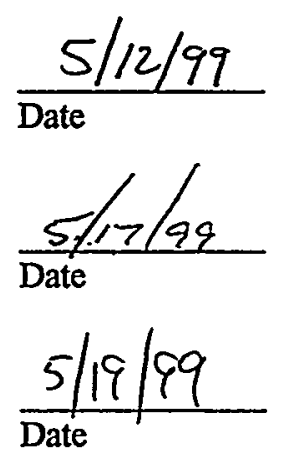

Westinghouse Savannah River Company

Savannah River Site

Aiken, SC 29808

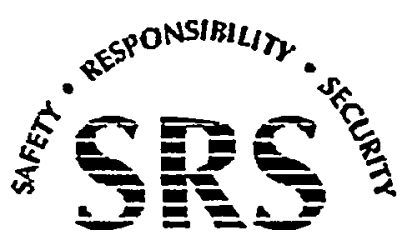




\section{DISCLAIMER}

This report was prepared as an account of work sponsored by an agency of the United States Government. Neither the United States Government nor any agency thereof, nor any of their employees, makes any warranty, express or implied, or assumes any legal liability or responsibility for the accuracy, completeness, or usefulness of any information, apparatus, product, or process disclosed, or represents that its use would not infringe privately owned rights. Reference herein to any specific commercial product, process, or service by trade name, trademark, manufacturer, or otherwise does not necessarily constitute or imply its endorsement, recommendation, or favoring by the United States Government or any agency thereof. The views and opinions of authors expressed herein do not necessarily state or reflect those of the United States Government or any agency thereof.

This report has been reproduced directly from the best available copy.

Available to DOE and DOE contractors from the Office of Scientific and Technical Information, P.O. Box 62, Oak Ridge, TN 37831; prices available from (615) 576-8401.

Available to the public from the National Technical Information Service, U.S. Department of Commerce, 5285 Port Royal Road, Springfield, VA 22161. 


\begin{abstract}
Many items in contamination areas do not become contaminated with radioactive materials during their normal use. These items eventually become low level radioactive waste unless they are proven to be free of contamination. For an unrestricted release from a contamination area, these items must receive radiological surveys to prove radioactive contamination is not present on any surface of the item. For items in areas with alpha contamination, this becomes even more difficult because of the very short-range and poor penetration of alpha radiation. Contamination on inaccessible surfaces, such as the internal surfaces of small diameter pipe, cannot be measured and therefore, the surfaces cannot be released for recycle or clean landfill disposal.

The Long Range Alpha Detection (LRAD) technology provides an alternative method for measuring alphaemitting contamination on surfaces that are accessible to ambient air. BNFL Instruments, Inc., developed and produced the IonSens ${ }^{\mathrm{TM}}$ monitoring system based on the principles of the (LRAD) technology.

This report describes the technology, system, and process that has been developed and tested. It also discusses the technology's advantages, disadvantages, system performance, and its effectiveness. A comparison to the baseline technologies as well as other competing technologies will be presented. This report will include a brief discussion of commercial availability and technology readiness for implementation and recommendations for its use.
\end{abstract}


WSRC-TR-99-00150

Revision 0

April 27, 1999

Page iv

This page intentionally left blank. 
WSRC-TR-99-00150

Revision 0

April 27, 1999

Page v

TABLE OF CONTENTS

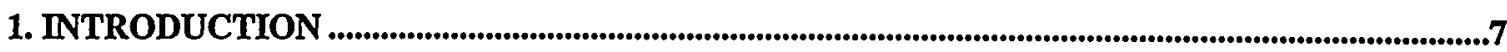

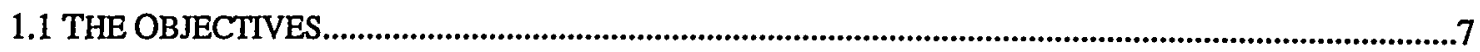

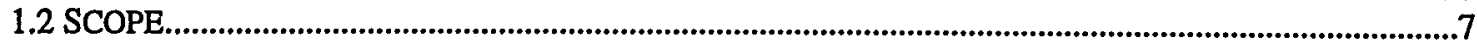

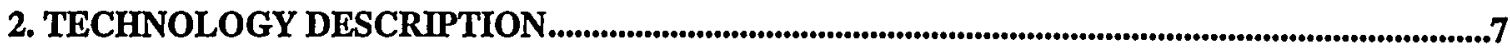

3. INSTRUMENTATION AND MEASUREMENTS.......................................................................................8

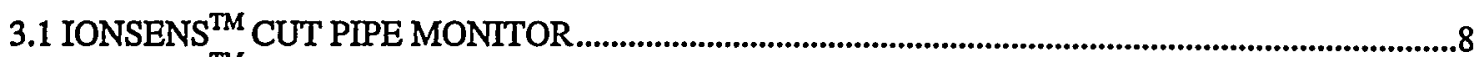

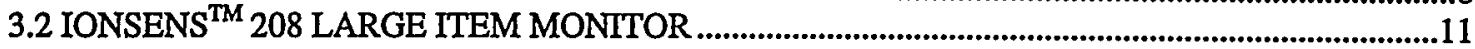

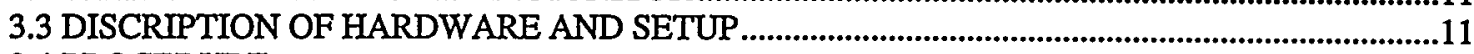

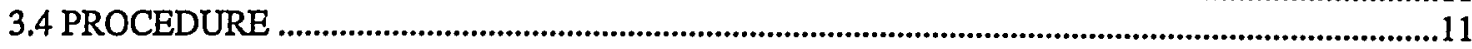

4. EVALUATION AND DEMONSTRATION...................................................................................................11

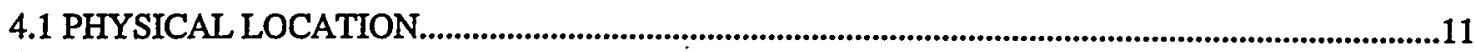

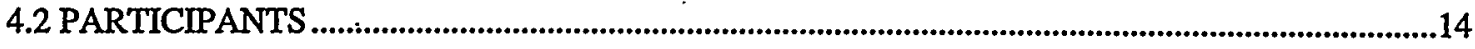

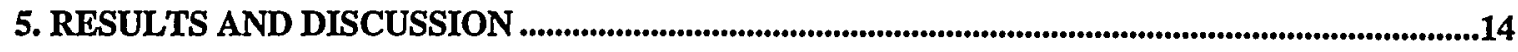

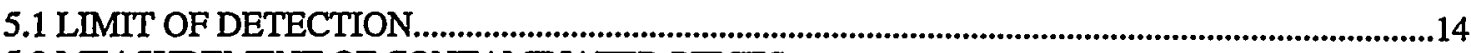

5.2 MEASUREMENT OF CONTAMINATED PIECES....................................................................15

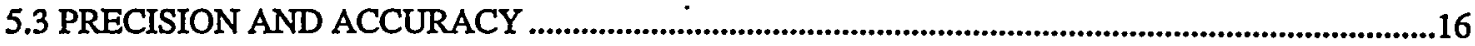

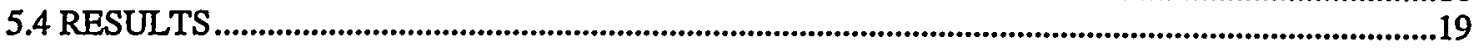

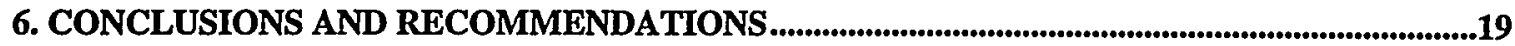


WSRC-TR-99-00150

Revision 0

April 27, 1999

Page vi

\section{LIST OF FIGURES}

Figure 1. A schematic diagram of the IonSens ${ }^{\mathrm{TM}}$ Cut Pipe Monitor..............................................................9 Figure 2. A photograph of the IonSens ${ }^{\mathrm{TM}}$ Cut Pipe Monitor..............................................................................9 Figure 3. A schematic diagram of the IonSens ${ }^{\mathrm{TM}} 208$ Large Item Monitor ...........................................10

Figure 4. A photograph of the IonSens ${ }^{\mathrm{TM}} 208$ Large Item Monitor Monitor............................................10

Figure 5. A photograph showing the setup of the system................................................................................12

Figure 6. A photograph showing loading of measurement chamber ............................................................13

Figure 7. A photograph showing examples of the items that were monitored

Figure 8. Control chart for the $500 \mathrm{dpm}$ standard ...................................................................................................18

Figure 9. Control chart for the $1000 \mathrm{dpm}$ standard ............................................................................................18

\section{LIST OF TABLES}

Table 1. Results obtained from measuring a $500 \mathrm{dpm}$ standard .........................................................................16

Table 2. Results obtained from measuring a 1000 dpm standard ......................................................................17

Table 3. Statistical parameters calculated for both standards..............................................................................17 
WSRC-TR-99-00150

Revision 0

April 27, 1999

Page 7

\title{
Evaluation and Demonstration of the BNFL Ionsens (U) By Saleem Salaymeh, et al
}

\author{
Westinghouse Savannah River Company \\ Savannah River Site \\ Aiken SC 29808
}

\section{INTRODUCTION}

Many items in contamination areas may not become contaminated with radioactive materials during their normal use. These items eventually become low level radioactive waste unless they are proven to be free of contamination. For an unrestricted release from a contamination area, these items must receive radiological surveys to prove radioactive contamination is and poor penetration of alpha radiation. Contamination not present on any surface of the item. For items in areas with alpha contamination, this becomes even more difficult because of the very short-range on inaccessible surfaces, such as the internal surfaces of small diameter pipe, cannot be measured and therefore, the surfaces cannot be released for recycle or clean landfill disposal.

Many facilities at the Savannah River Site were used to manufacture products containing alpha-emitting radionuclides. This involved precise weigh-out of materials and enrichment, melting together into alloy, extruding the alloy into tubes, dissolution, solvent extraction and various steps involving machining, welding, and chemical cleaning. These activities contaminated many areas and components with alphaemitting radionuclides. Although many of these components have no further value and can be disposed as low level waste, there are some items that are still useable and which could be recycled. There is also a financial incentive to be able to dispose of excess items as conventional sanitary waste if its contamination level is below free release limits. In order to free release small components from a contamination area, SRS requires that a detailed survey be conducted to "prove" the absence of contamination or to determine that the contamination is below free release limits.

The Long Range Alpha Detection (LRAD) technology provides an alternative method for measuring alphaemitting contamination on surfaces that are accessible to ambient air. BNFL Instruments, Inc., developed and produced the IonSens ${ }^{T M}$ monitoring system based on the principles of the LRAD technology.

\subsection{The Objectives}

The primary objective of this study is to evaluate and demonstrate the LRAD technology and to determine its possible use for monitoring potentially alpha contaminated objects for free release.

\subsection{Scope}

The scope of this study is to carry out an evaluation and demonstration of this technology in order to determine the possibility of its deployment at SRS and across the DOE complex. The IonSens ${ }^{\mathrm{TM}}$ system will be evaluated and demonstrated in two areas at SRS. The first area is C-Area Decontamination Facility and the second is 321-M Facility.

\section{TECHNOLOGY DESCRIPTION}

The Long Range Alpha Detection or 'LRAD' technique depends on the measurement of air ions created by alpha particles rather than direct detection of the alpha particles themselves. Thus, this technique is not limited by the short-range in air of this radiation. Alphas from alpha-emitting contamination lose all of their energy in a few centimeters of air. This energy goes into the ionization of air molecules, so that the number of ions created is directly proportional to the 
amount of alpha-emitting contamination (i.e. uranium in this application) which is exposed. These air ions are transported in an air current (or via an applied electric field) and electrically detected by the LRAD ion detector. A small electrical current is produced in this detector which is proportional to the number of ions in the air and hence the amount of exposed alpha contamination.

The LRAD technology was developed at Los Alamos National Laboratories (LANL) and has been demonstrated to be a highly sensitive method of measuring alpha activity. Alpha particles are highly ionizing radiation which lose their energy by creating electron/ion pairs in the medium they traverse. In air they have a very short range of approximately $4 \mathrm{~cm}$. In most gases an energy of approximately $35 \mathrm{eV}$ is required to produce an electron/ion pair and thus a typical $5 \mathrm{MeV}$ alpha particle will produce around 150,000 ion pairs. These ions can be collected and measured directly as a current of several femto amp (fA $=1 \times 10^{-15} \mathrm{~A}$ ) per Bq.

The ions can be transported over a range of several meters in the air current created by using a fan to pass air over the potentially contaminated item to be measured. The air and any ions produced are then transported to a collection grid (or grids). The ions collected are attracted to the grids by an electrostatic field and cause a small current to flow, which is proportional to the alpha activity present on the item. This method relies on the fact that it takes several seconds for half of the ions in the air to recombine. Contamination in a pipe many meters long can therefore be measured if the airflow is sufficient to transport the ions from the contamination position to the measurement grid within this time.

The technique will not work if the item to be measured has a surface charge, e.g. plastic. The surface charge will tend to attract ions and thus reduce the measured ionization current. It is assumed that the alpha particles can escape from where they are emitted into the air, i.e. not covered by paint, grease or liquid. Alpha particle must also deposit a large fraction of its energy into the air, i.e. cannot be located in very small grooves etc.

\section{INSTRUMENTATION and MEASUREMENTS}

The instrument consists of two major parts: the IonSens ${ }^{\mathrm{TM}}$ Cut Pipe Monitor and the IonSens ${ }^{\mathrm{TM}} 208$ Large Item Monitor. The following is a description of the operation and parameters of the equipment:

\subsection{IonSens $^{\mathrm{TM}}$ Cut Pipe Monitor}

The Cut Pipe Monitor is an "airflow" type LRAD detector. Pipes are placed in the measurement chamber and air passes over and through the pipe, carrying the ions to the ion detector. Figure 1 shows a schematic diagram of the Cut Pipe Monitor. Figure 2 shows a photograph of the IonSens ${ }^{\mathrm{TM}}$ Cut Pipe Monitor

The basic operation of this instrument involves ambient air entering through a filter, passing around the object to be monitored, carrying the ionized molecules to the ion detector, and exiting through a fan. During initialization of the instrument, the IonSens ${ }^{\mathrm{TM}}$ performs a variety of diagnostic routines to confirm the correct operation of the instrument hardware.

The pipes and poles to be measured are placed in a series of air tight measurement modules. These modules are 2 meters in length and the length of the measured pipe determines the number of modules (up to three) that are used for the measurement. The pipe rests on an adjustable metallic cradle, to ensure pipes of varying diameters are positioned in the center of the measurement module.

The upper half of the measurement module is a hinged lid and this allows access to the measured pipe. The lid can be easily opened and closed by an operator and is equipped with a proximity switch to allow the system to establish the lid's status. 


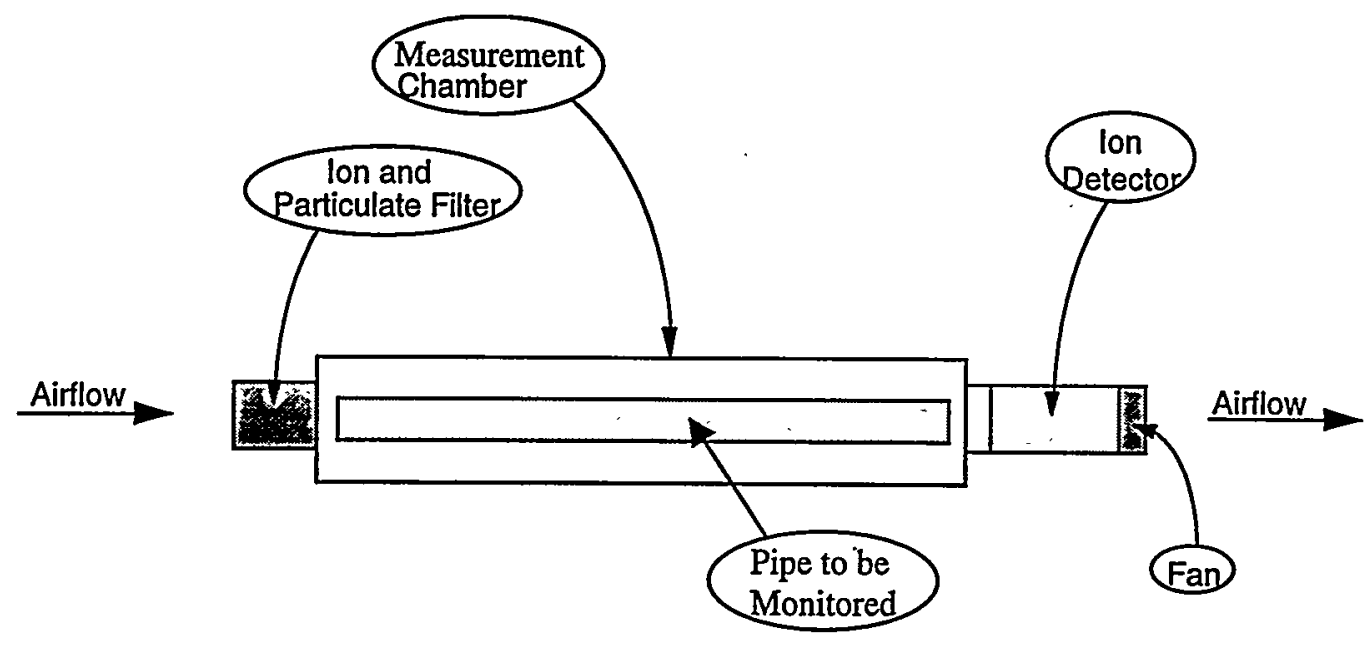

Figure 1. A schematic diagram of the Cut Pipe Monitor

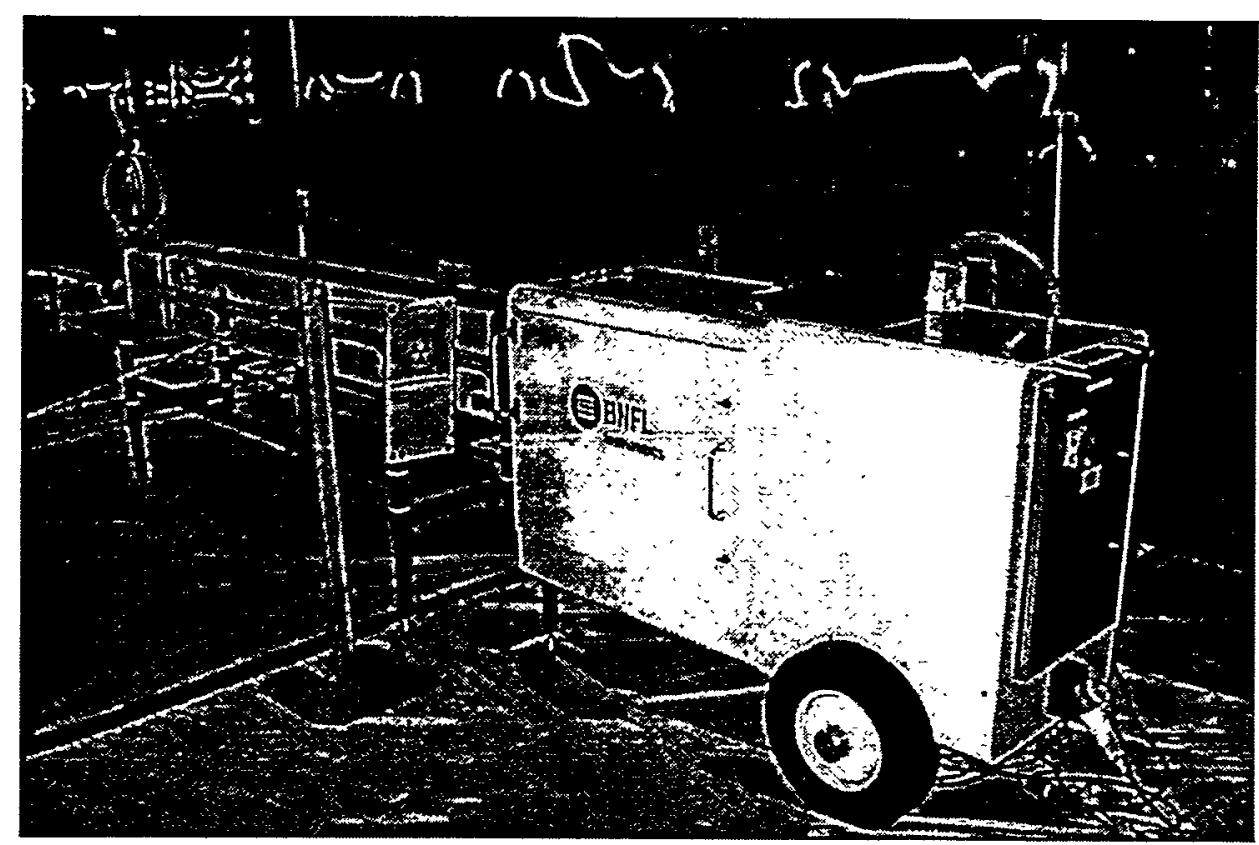

Figure 2. Shows a photograph of the IonSens ${ }^{\mathrm{TM}}$ Cut Pipe Monitor 
WSRC-TR-99-00150

Revision 0

April 27, 1999

- Page 10

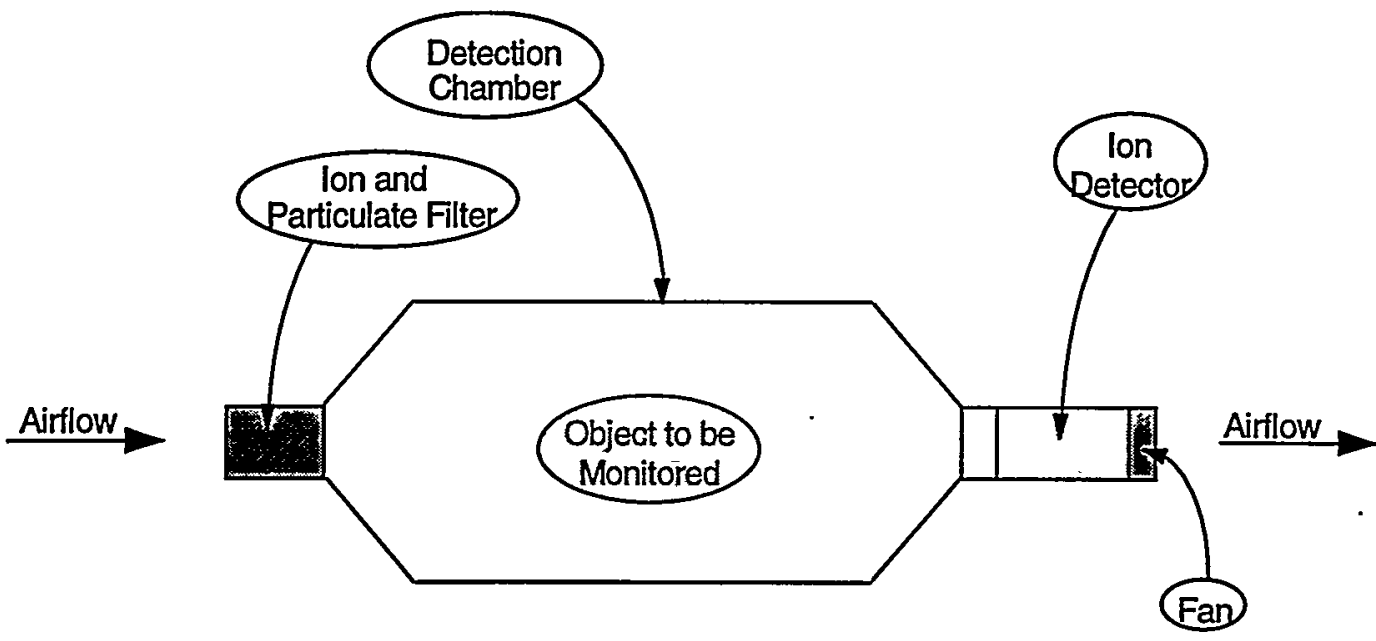

Figure 3. A schematic diagram of the Large Item Monitor

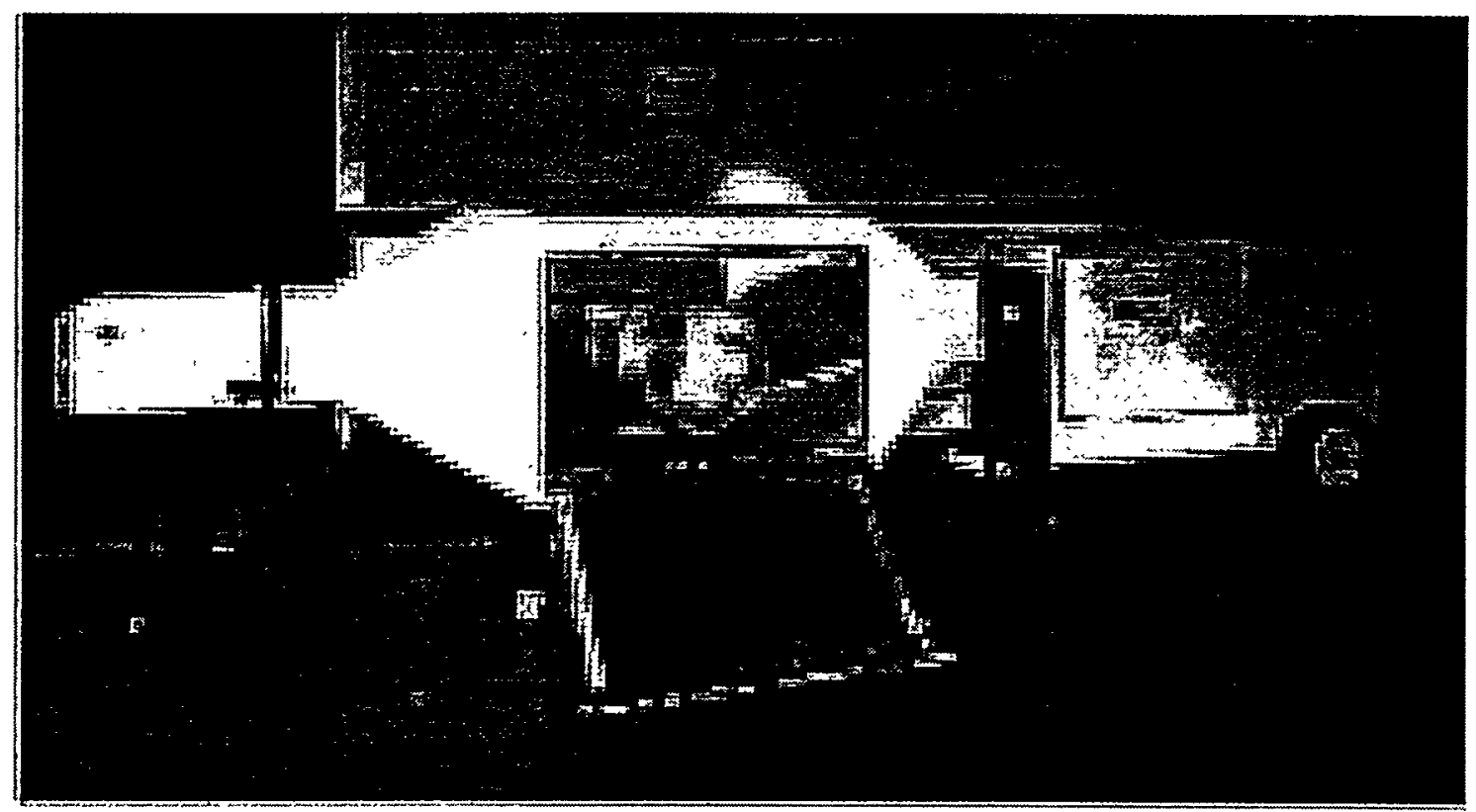

Figure 4. Shows a photograph IonSens ${ }^{\mathrm{TM}} 208$ Large Item Monitor 


\subsection{IonSens ${ }^{\mathrm{TM}} 208$ Large Item Monitor}

The IonSens" 208 Large Item Monitor is an "airflow" type LRAD detector similar to the Cut Pipe Monitor. Objects are placed in the measurement chamber and air passes over and through the pipe, carrying the ions to the ion detector for the measurement of items such as miscellaneous scrap metal, ducting, metal plates, tools etc. The only difference between the two parts is the measurement chamber. Figure 3 shows a schematic diagram of the Large Item Monitor. Figure 4 shows a photograph IonSens ${ }^{\text {TM }} 208$ Large Item Monitor

\subsection{Description of Hardware Setup}

The IonSens ${ }^{\mathrm{TM}}$ pipe monitor comprises of the main detector unit, measurement modules, and an inlet filter unit. Three 2 meter pipe modules can be used in combination to monitor pipes up to 6 meters in length. Measurement modules are connected to the inlet side of the detector unit. The footprint of the pipe measurement chamber and detector unit measures approximately 8 meters $\times 1$ meter (maximum). The footprint of the large item measurement chamber and detector unit measures approximately 5 meters $\times 1.5$ meters. The inlet filter is connected to the air inlet side of the measurement modules. A laptop personal computer (PC) provides support software for equipment operation. Both configurations require an area for loading and unloading materials and operator access to the equipment.

\subsection{Procedure}

To start a routine measurement, the operator initiates the sequence from the control PC. Ambient air enters the measurement module(s) through a filter, which removes any externally generated ions and particulate matter. The de-ionized air passes around and through the pipe and the air current collects and carries any alpha generated ions to the ion detector. Since this type of LRAD detector can measure all of the ions produced around a pipe simultaneously, the Cut Pipe Monitor is sensitive to all the surface contamination in a single measurement. This total alpha measurement is compared against the free release classification criteria specified by the operator. If the criteria are met, the sequence terminates, otherwise an iris seal is closed around the pipe to allow an internal surface activity measurement to be taken. The results are stored on the PC hard disc and can be displayed on the PC monitor or can be printed. The results will show:

- Total activity

- External activity

- Internal activity

- Pipe classification

\section{EVALUATION AND DEMONSTRATION SUMMARY}

\subsection{Physical Location}

The IonSens ${ }^{\mathrm{TM}}$ evaluation and demonstration was held in two facilities at SRS; at the 105-C Decontamination Facility in C-Area for one week and the 321-M Fuel Fabrication Facility located at the Savannah River.Site for three weeks. The Decontamination Facility in C-Area has a variety of decon equipment used for decontaminating items and components for all the facilities at the site. The 321-M facility was used to manufacture fuel and target assemblies for irradiation in the site's production reactors. The facility was shut down in 1992 and the process area remains a high contamination area contaminated with highly enriched uranium (HEU).

Figure 5 shows a photograph showing the setup of the system. Figure 6 shows a photograph showing the loading of measurement chamber. Figure 7shows a photograph showing example of the items that were monitored. 
During operation, many miscellaneous items and components were used in the process area but did not become contaminated with HEU. These items are potential candidates for recycle or unrestricted release, but must be proven clean before releasing from the contamination area. Since HEU was the only radionuclide used in the 321-M facility, release limits were based on uranium removable limits of 1000 disintegrations per minute (dpm) $/ 100 \mathrm{~cm}^{2}$ and $5000 \mathrm{dpm} / 100 \mathrm{~cm}^{2}$ (total) per 5Q Radiological Control, Table 2-2, Summary of Contamination Values. This level was well within the minimum detection limits of the IonSens ${ }^{\mathrm{TM}}$ monitoring system. The limit of detection of the system is not low enough for the removable transuranic radionuclides release limits of $20 \mathrm{dpm} / 100 \mathrm{~cm}^{2}$ and $500 \mathrm{dpm} / 100 \mathrm{~cm}^{2}$ (total) per $5 \mathrm{Q}$ Radiological Control, Table 2-2, Summary of Contamination Values.

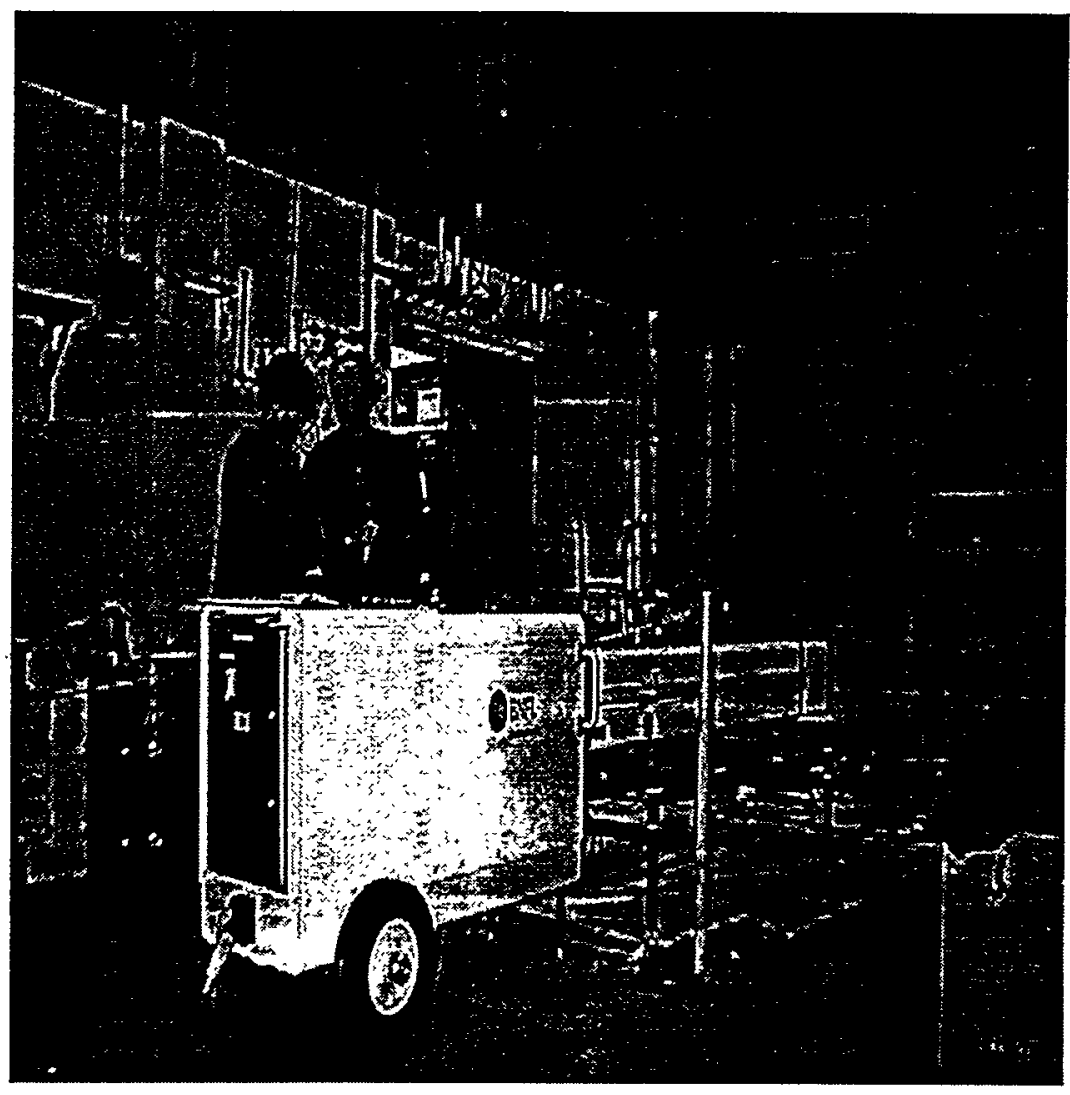

Figure 5. A photograph showing the setup of the system. 
WSRC-TR-99-00150

Revision 0

April 27, 1999

Page 13

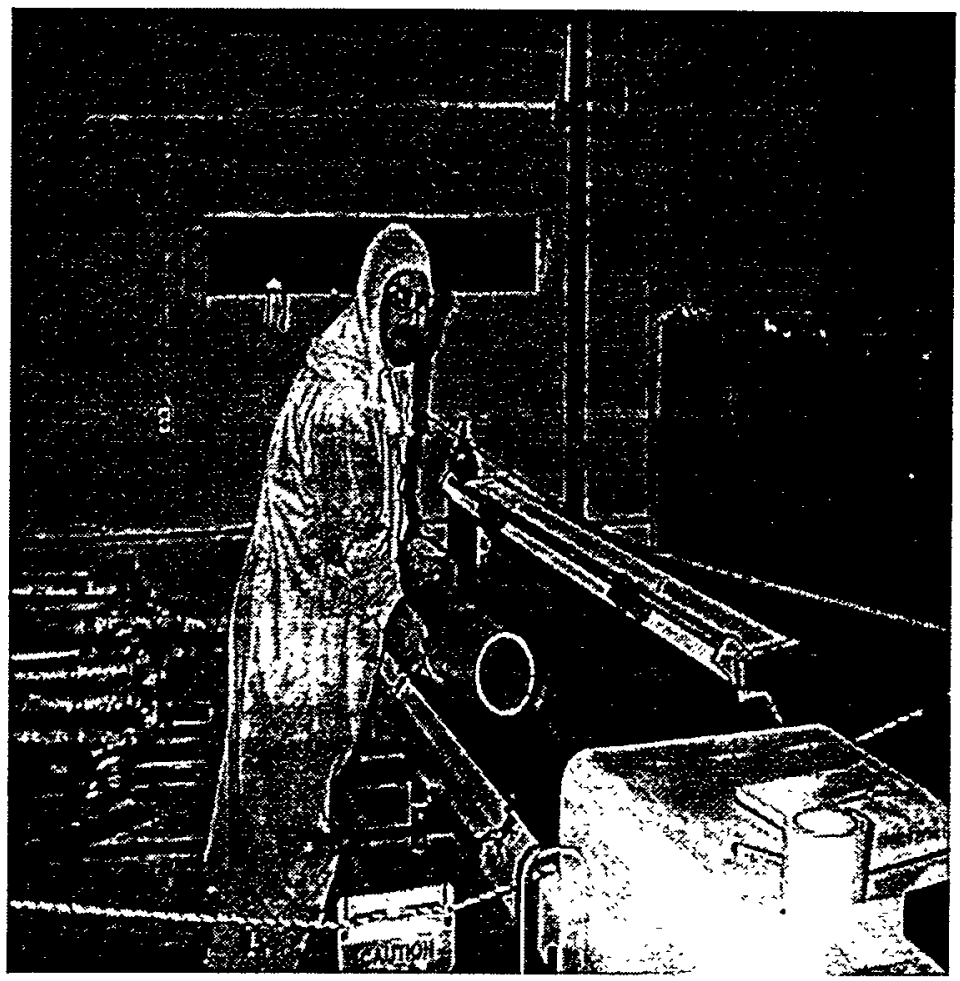

Figure 6. A photograph showing loading the measurement chamber.

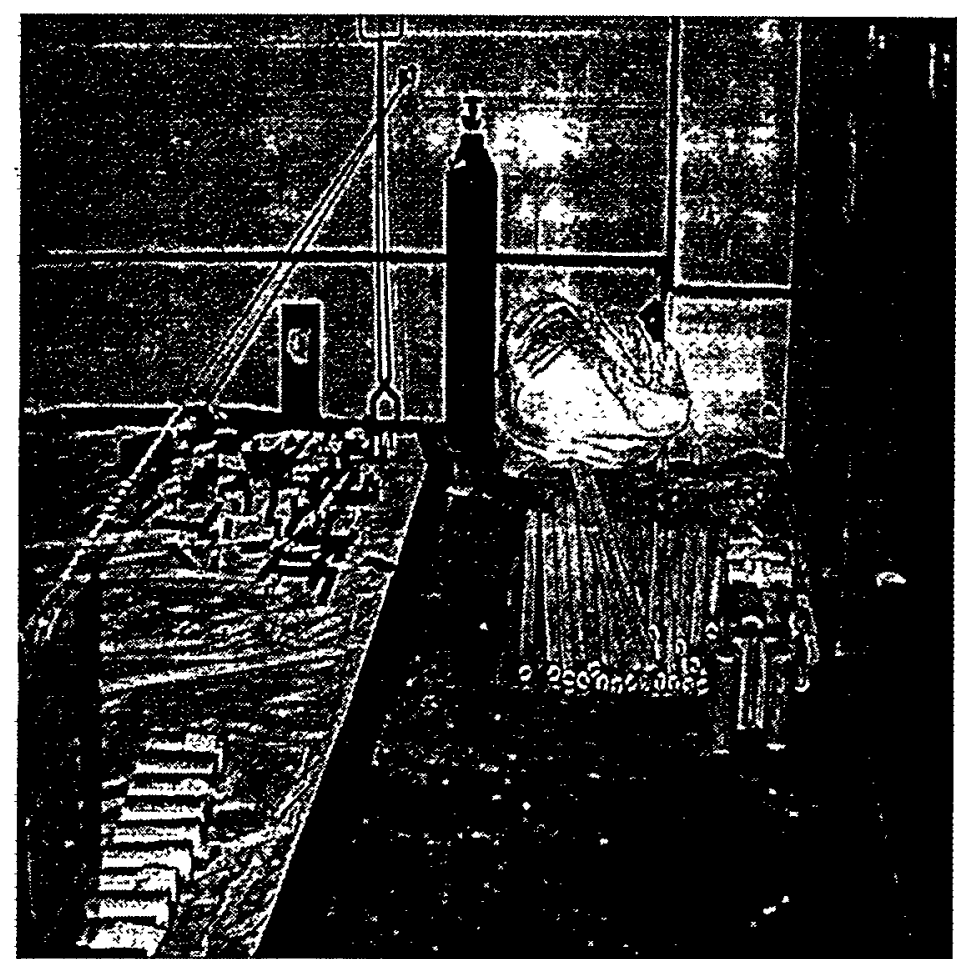

Figure 7. A photograph showing examples of the items that were monitored. 
WSRC-TR-99-00150

Revision 0

April 27, 1999

Page 14

\subsection{Participants}

The evaluation and demonstration participants were:

- BNFL Instruments, Inc.

- Solid Waste Division

- Health Physics Technology

- Health Physics - Facilities D\&D

- Facilities Decommissioning Division

- Savannah River Technology Center

\section{RESULTS AND DISCUSSION}

As stated above, the system consists of two major parts: the IonSens ${ }^{\mathrm{TM}}$ Cut Pipe Monitor and the IonSens ${ }^{\mathrm{TM}}$ 208 Large Item Monitor. It was determined that using the IonSens ${ }^{\mathrm{TM}}$ pipe monitor (main detector unit, one measurement module, and an inlet filter unit) would be all we need to use in order to evaluate and demonstrate this technology. All the results presented in this report were obtained using the IonSens ${ }^{\mathrm{TM}}$ Pipe Monitor with one measurement module. All items (including standards) were measured by placing them on a mesh tray in the center of the measurement module. It is important to point out that the release limits were based on uranium removable limits of $1000 \mathrm{dpm} / 100 \mathrm{~cm}^{2}$. Our test results were based on the removable contamination level on a surface area of $100 \mathrm{~cm}^{2}$, this meant that the measurements did not take into consideration the surface area of the item being monitored.

Approximately 500 items weighing 2000 pounds total were monitored by the IonSens ${ }^{\mathrm{TM}}$ system. The sizes and shapes of the items varied, but fit into one section of the pipe measurement chamber. A mesh tray supported items such as hand tools and short tubular pieces that were too small for the chamber's support system. Using this setup, multiple items were monitored during a single measurement cycle.

Of the 500 items monitored, approximately 300 items, or 1000 pounds, were identified for free release based on uranium free release criteria. The 300 items included approximately 500 pounds of lead with contamination levels below free release levels. A manual free release survey confirmed the IonSens ${ }^{\mathrm{TM}}$ results. An average measurement cycle for the IonSens ${ }^{\mathrm{TM}}$ system is approximately seven minutes. A cycle includes loading the measurement chamber, monitor time, and unloading the chamber. The IonSens ${ }^{\mathrm{TM}}$ system requires occasional standardization and background checks. The detector collector plates are sensitive to dirt and foreign matter, but if kept clean, are not high maintenance items. Normal system operation requires little maintenance.

\subsection{Limit of Detection}

The limit of detection (LOD) depends on the background fluctuations and the efficiency (Eff) of the detector. For the IonSens Pipe Monitor, this is calculated as follows:

$$
L O D=n \sqrt{2} \frac{\sigma_{B}}{E f f},
$$

Where $\mathrm{n}$ is the number of standard deviations used, $\sigma_{\mathrm{B}}$ is the standard deviation of the background determined during the background measurement routine, and Eff is the efficiency factor of the detector determined during the standardization routine.

The standard error on a measurement is calculated from: 


$$
\sigma_{T}=\sqrt{\left(\frac{\sigma_{B}}{E f f}\right)^{2}+\left(\frac{\sigma_{M}}{E f f}\right)^{2}}
$$

Where $\sigma_{M}$ is the standard error on the measurement. If we put a completely clean object into the device,

$$
\sigma_{M}=\sigma_{B},
$$

Simplifying the equation to:

$$
\sigma_{T}=\sqrt{2} \frac{\sigma_{B}}{E f f}
$$

The total activity is calculated as

$$
T=\frac{\bar{M}-\bar{B}}{E f f}+n \sigma
$$

Where $\mathrm{M}$ is the mean of the electrometer readings during a measurement and $\mathrm{B}$ is the mean of the electrometer readings during a background measurement.

Given that $n \sigma_{\mathrm{T}}=\mathrm{LOD}$, and that M-B is constrained to positive values, it is clear that for samples which are essentially exempt from any contamination, the system can only report a figure for total activity which is at or above the LOD.

The number of standard deviations, $n$, used in these calculations is a maintainable constant. It was set at 3 during the IonSens demonstration.

\subsection{Measurement of Contaminated Pieces}

In a real measurement the error on the activity is calculated using the full equation

$$
\sigma_{T}=\sqrt{\left(\frac{\sigma_{B}}{E f f}\right)^{2}+\left(\frac{\sigma_{M}}{E f f}\right)^{2}}
$$

And the total activity is thus given by

$$
T=\frac{\bar{M}-\bar{B}}{E f f}+n \sigma_{T}
$$

The activity displayed by the instrument is therefore an upper limit on the possible activity on the item.

A further cause of a difference between the measured activity and the actual activity is the geometrical uncertainty. The instrument is calibrated as if the activity in the chamber were at the position of the standardization source, the least sensitive measurement position. This is because the instrument cannot give the position of the activity so we have to assume it is located in the worst measurement position. 
WSRC-TR-99-00150

Revision 0

April 27, 1999

Page 16

Therefore we would expect the system to overestimate the activity present. This gives confidence that any item classified as suitable for free release is definitely free release.

\subsection{Precision and Accuracy}

National Institute of Standards and Technology traceable standards with known alpha activity were used to determine the precision and accuracy of the IonSens ${ }^{\mathrm{TM}}$ system. Table 1 shows the results obtained from measuring a $500 \mathrm{dpm}$ standard as the measured activity in dpm with no uncertainty, the percent difference from the value of the standard, and the upper activity limit including $3 \sigma$ uncertainty. Table 2 shows the results obtained from measuring a $1000 \mathrm{dpm}$ standard as the measured activity in dpm with no uncertainty, the percent difference from the value of the standard, and the upper activity limit including $3 \sigma$ uncertainty.

The precision of the system is expressed in terms of Percent Relative Standard Deviation (\%RSD) and its accuracy is expressed in terms of average percent difference (\%Diff) from the original value of the standard. The precision of the system ranged between 13.17 and 24.36 for results obtained from the 1000 $\mathrm{dpm}$ and the $500 \mathrm{dpm}$ standards respectively. The accuracy of the system is expressed in terms of average percent difference (\%Diff) from the original value of the standard. The accuracy of the system ranged between 5.97 and 19.25 for results obtained from the $1000 \mathrm{dpm}$ and the $500 \mathrm{dpm}$ standards respectively. Table 3, shows statistical parameters calculated for both standards. For the $500 \mathrm{dpm}$ standard, the average measured activity was $596.25 \mathrm{dpm}$ with a standard deviation of 145.27 , an average percent difference of 19.25 , and a percent relative standard deviation of 24.36 . For the $1000 \mathrm{dpm}$ standard, the average measured activity was $1059.65 \mathrm{dpm}$ with a standard deviation of 139.58 , an average percent difference of 5.97 , and a percent relative standard deviation of 13.17 .

Overall, the pooled standard deviation for the system is 141.57 and the overall average percent difference is 12.61. The average percent relative standard deviation for the system is 18.77.

\begin{tabular}{|c|c|c|c|}
\hline $\begin{array}{c}\text { Measurement } \\
\text { number using } \\
\text { a 500 dpm } \\
\text { source }\end{array}$ & $\begin{array}{c}\text { Measured } \\
\text { Activity in } \\
\text { (dpm) }\end{array}$ & $\begin{array}{c}\text { Upper Activity } \\
\text { Limit at 3 } \sigma \\
\text { confidence } \\
\text { level }\end{array}$ & $\begin{array}{c}\text { Percent- } \\
\text { Diff. }\end{array}$ \\
\hline Meas 1 & 463 & 840 & -7.4 \\
\hline Meas 2 & 503 & 1020 & 0.6 \\
\hline Meas 3 & 625 & 1140 & 25 \\
\hline Meas 4 & 530 & 1140 & 6 \\
\hline Meas 5 & 468 & 1020 & -6.4 \\
\hline Meas 6 & 494 & 960 & -1.2 \\
\hline Meas 7 & 845 & 1440 & 69 \\
\hline Meas 8 & 548 & 1080 & 9.6 \\
\hline Meas 9 & 842 & 1320 & 68.4 \\
\hline Meas 10 & 736 & 1260 & 47.2 \\
\hline Meas 11 & 505 & 1020 & 1 \\
\hline
\end{tabular}

Table 1. Results obtained from measuring a $500 \mathrm{dpm}$ standard. 


\begin{tabular}{|c|c|c|c|}
\hline $\begin{array}{c}\text { Measurement } \\
\text { number using } \\
\text { a 1000 dpm } \\
\text { source }\end{array}$ & $\begin{array}{c}\text { Measured } \\
\text { Activity } \\
\text { (dpm) }\end{array}$ & $\begin{array}{c}\text { Upper-Activity } \\
\text { Limit at 3 } \sigma \\
\text { confidence } \\
\text { level }\end{array}$ & $\begin{array}{c}\text { Percent } \\
\text { Diff. }\end{array}$ \\
\hline Meas 1 & 946 & 1500 & -5.4 \\
\hline Meas 2 & 888 & 1500 & -11.2 \\
\hline Meas 3 & 930 & 1440 & -7 \\
\hline Meas 4 & 927 & 1440 & -7.3 \\
\hline Meas 5 & 1011 & 1620 & 1.1 \\
\hline Meas 6 & 917 & 1380 & -8.3 \\
\hline Meas 7 & 1076 & 1560 & 7.6 \\
\hline Meas 8 & 1081 & 1620 & 8.1 \\
\hline Meas 9 & 1088 & 1620 & 8.8 \\
\hline Meas 10 & 898 & 1500 & -10.2 \\
\hline Meas 11 & 924 & 1440 & -7.6 \\
\hline Meas 12 & 1027 & 1500 & 2.7 \\
\hline Meas 13 & 1347 & 1740 & 34.7 \\
\hline Meas 14 & 1180 & 1740 & 18 \\
\hline Meas 15 & 1210 & 1680 & 21 \\
\hline Meas 16 & 1202 & 1860 & 20.2 \\
\hline Meas 17 & 1260 & 1740 & 26 \\
\hline Meas 18 & 1256 & 1800 & 25.6 \\
\hline Meas 19 & 997 & 1440 & -0.3 \\
\hline Meas 20 & 1028 & 1500 & 2.8 \\
\hline & & & \\
\hline & & & \\
\hline
\end{tabular}

Table 2. Results obtained from measuring a $1000 \mathrm{dpm}$ standard.

\begin{tabular}{|c|c|c|c|c|}
\hline $\begin{array}{c}\text { Standard } \\
\text { (dpm) }\end{array}$ & $\begin{array}{c}\text { Average } \\
\text { measured } \\
\text { Activity }\end{array}$ & Stdev & $\begin{array}{c}\text { Ave } \\
\% \text { diff }\end{array}$ & \%RSD \\
\hline 500 & 596.27 & 145.27 & 19.25 & 24.36 \\
\hline 1000 & 1059.65 & 139.58 & 5.97 & 13.17 \\
\hline Average & N/A & $141.57^{\star}$ & 12.61 & 18.77 \\
\hline
\end{tabular}

Table 3. Statistical parameters calculated for both standards.

* pooled standard deviation 
WSRC-TR-99-00150

Revision 0

April 27, 1999

Page 18

Preclsion Using $\mathbf{5 0 0} \mathrm{dpm}$ Standard

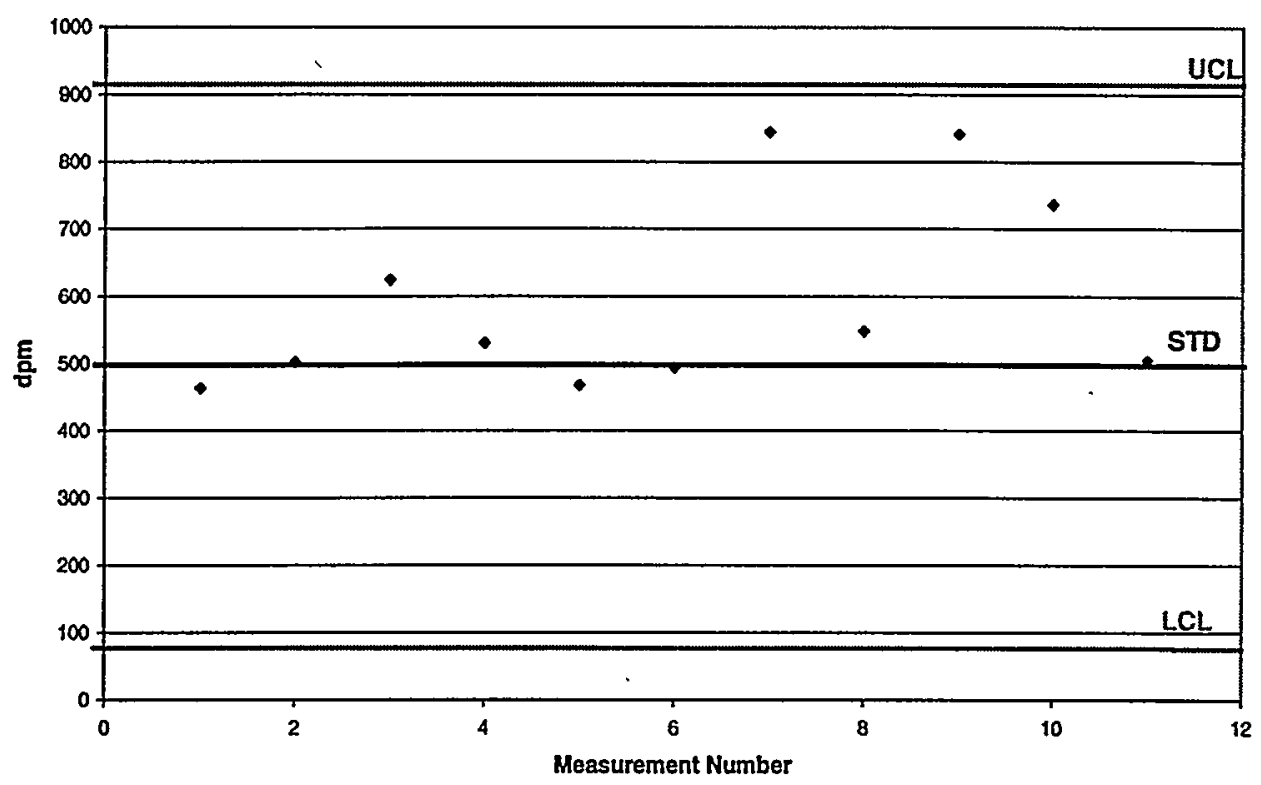

Figure 7. Control chart for the $\mathbf{5 0 0} \mathbf{d p m}$ standard.

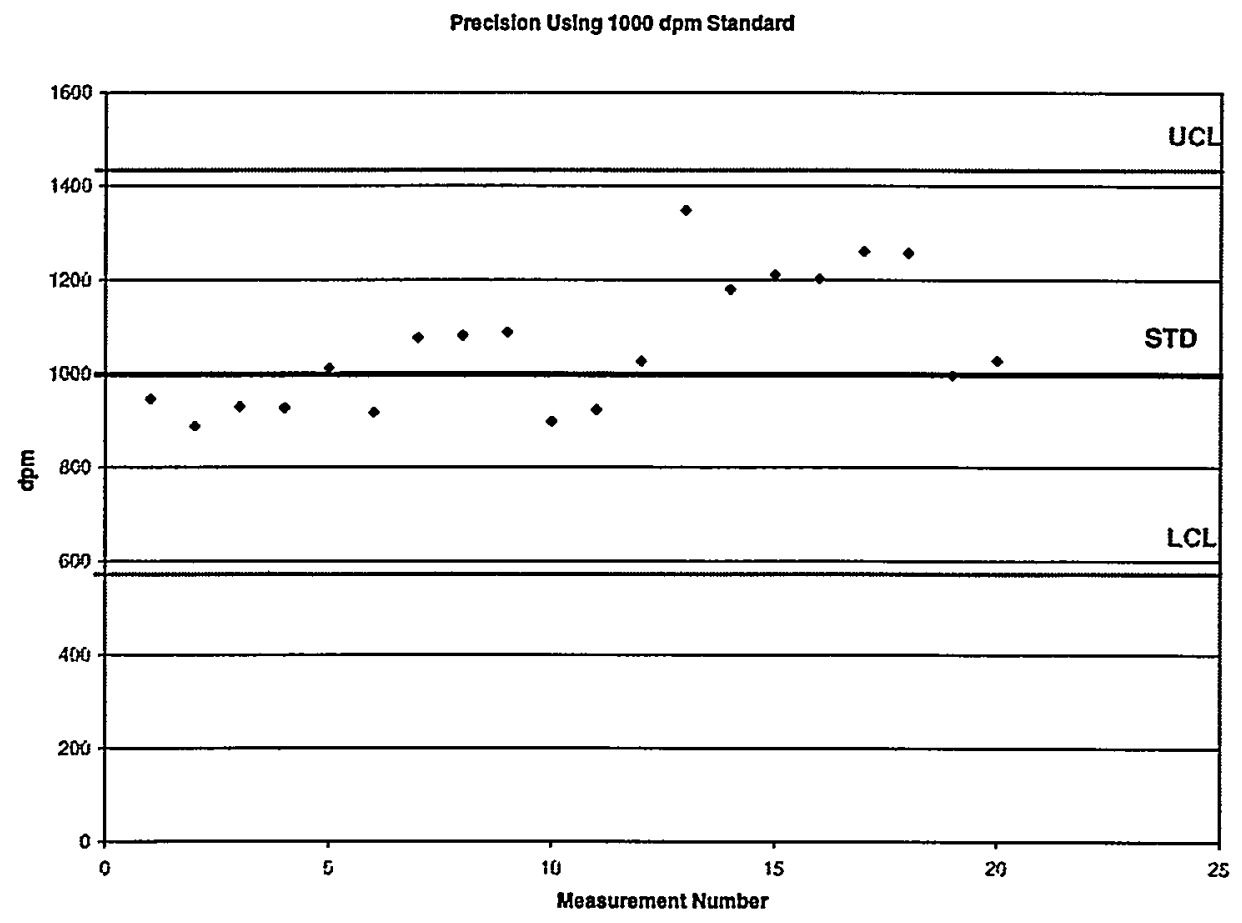

Figure 8. Control chart for the $\mathbf{1 0 0 0} \mathrm{dpm}$ standard. 
WSRC-TR-99-00150

Revision 0

April 27, 1999

Page 19

\subsection{Results}

Preliminary data evaluation indicates the IonSens ${ }^{\mathrm{TM}}$ system is faster than hand surveying for larger items and multiple items run in a single measurement cycle. Single item measurements of small items may be longer than the time required to hand survey the item. The minimum sensitivity of the system using one pipe measurement chamber was $500 \mathrm{dpm} / 100 \mathrm{~cm}^{2}$. Planned improvements (per BNFL) of the operating software are expected to lower the sensitivity level to $200 \mathrm{dpm} / 100 \mathrm{~cm}^{2}$.

Of the 500 items monitored using the IonSens ${ }^{\mathrm{TM}}$ system, approximately 300 items, or 1000 pounds, were identified for free release based on uranium free release criteria. The 300 items included approximately 500 pounds of lead with contamination levels below free release levels. A manual free release survey confirmed the IonSens ${ }^{\mathrm{TM}}$ results to be correct. An average measurement cycle for the IonSens ${ }^{\mathrm{TM}}$ system is approximately seven minutes. A cycle includes loading the measurement chamber, monitor time, and unloading the chamber.

\section{CONCLUSIONS AND RECOMMENDATIONS}

The instrument performance was good when used to screen items with potential contamination from uranium facilities. The IonSens ${ }^{\mathrm{TM}}$ system detection levels were well within the range of the uranium free release limits. However, the limits for other transuranic radionuclides are lower and are below the limit of detection of the system.

Approximately 60 (300 items) percent of the items measured, were identified for free release based on uranium free release criteria. A manual free release survey confirmed the IonSens ${ }^{\mathrm{TM}}$ results to be consistent. Some of the advantages of the system are:

- The ability to survey areas such as the internal surface of pipe where hand probe and smears are not possible,

- Provides computer printout of surveys results, and

- The IonSens ${ }^{\mathrm{TM}}$ system is much faster than hand surveys depending on the number of items monitored during the same run or the size of the item.

The IonSens ${ }^{\mathrm{TM}}$ monitoring system is optimized for use for the following purposes:

- Verifying contamination on surfaces inaccessible to hand probing and smearing but accessible to a free flow of air,

- Confirming the lack of contamination on materials that are candidates for free release but must be proven clean, and

- Larger items where detailed hand probing and smearing requires additional time and number of smears.

In general, the data collected during the evaluation and demonstration of the system indicates that the system can be used as a screening tool to segregate items into potentially contaminated and clean. The Health Physics Technology department at SRS is fully supportive of the IonSens ${ }^{\text {TM }}$ system. As indicated by HPT, the first phase of acceptance will allow the system to be used as a screening tool to identify items for free release using uranium free release limits. Additional production experience will be needed for full acceptance as an alternative to hand surveys. When operating software is available to measure contamination levels approaching the release levels of plutonium and other radionuclides, further evaluation will be made for those purposes.

The following is a list of limitations and areas that need further development to make the IonSens ${ }^{\mathrm{TM}}$ monitoring system more useful for future use:

- The limit of detection is not low enough for the removable transuranic radionuclides release limits.

- Materials with surface charges, such as plastics, tend to attract ions and thus reduce the measured ionization current. 
- Alpha particles will not penetrate paint, grease, or liquid. Items are to be free of these materials before monitoring.

- Irregularly shaped items that can obstruct airflow.

- The Cut Pipe Monitor and 208 Large item monitor were not designed to monitor multiple small items and may not give the sensitivity levels required for these items. A small item measurement chamber can be designed for small multiple items.

- Ion pairs may recombine in extended lengths of small diameter pipe causing an erroneous reading. 